\title{
TREATMENT SATISFACTION: A NEGLECTED BUT IMPORTANT OUTCOME MEASURE IN OLDER PEOPLE WITH TYPE 2 DIABETES
}

\author{
H. Langerman ${ }^{1,2}$, R. Gadsby ${ }^{3}$
}

\begin{abstract}
Objective: To investigate the effect of comprehensive geriatric care (CGC) in elderly referred to a rehabilitation unit. This article describes the considerations behind the study. Design: Participants were randomized to either CGC or standard care. Setting: Participants were recruited from two community care rehabilitation units in Aarhus Municipality, Denmark, in the period between 2012 and 2015. Participants: Inclusion: Elderly patients aged 65 and older admitted from home or hospital. Exclusion: Persons receiving palliative care or assessed by a geriatrician during the past month. Intervention: Medical history, physical examination, blood tests, medication adjustment and follow-up by a geriatrician. The control group received standard care with the general practitioners (GPs) as back-up. Outcomes: Primary outcome: Hospital contacts drawn from national registers. Secondary outcomes: GPs contacts, institutionalization, medication status and mortality collected from national registers and Activities of daily living (ADL), physical and cognitive function and quality of life measures collected by a blinded occupational therapist. All outcomes were assessed at day 10, 30 and 90 after arrival at the rehabilitation unit. Conclusion: A new model of care for elderly referred to community rehabilitation was developed and implemented. The potential benefits of this model were compared with usual care in a community rehabilitation unit in a pragmatic randomized clinical trial. We hypothesized that the geriatrician-performed CGC in elderly referred to a rehabilitation unit will reduce the hospital contacts by $25 \%$ without increase in mortality and in contacts to GPs and home care services. We expect that this model will prevent deterioration in ADL, and physical and cognitive functioning, and reduce the risk of institutionalization. If the results are positive, community rehabilitation services should be encouraged to change their routines for treatment of this population accordingly..
\end{abstract}

Key words: Randomized controlled trial, Comprehensive geriatric care, rehospitalization, rehabilitation, activity of daily living.

\section{Introduction}

Older people are the fastest growing segment of the population, responsible for a large portion of the use of health care services, and a large and growing section of the population with diabetes. They are not a uniform group and can be broadly classified into those entering old age (generally 60 years and above), a transitional phase between healthy active life and frailty (the seventh or eighth decade), and frail older people (late old age) (1). Diabetes is up to five times more prevalent in patients aged 65 years or older, compared with patients below the age of $65(2,3)$. Recent estimates suggest that up to 1 in 5 older people have diabetes and that a similar proportion may have undiagnosed diabetes (4).

The management of older people with diabetes presents unique challenges. Observational studies suggest

1. Beds \& Herts Postgraduate Medical School, Luton, UK; 2. Merck Sharp and Dohme, UK; 3. University of Warwick Medical School, Coventry, UK.

Corresponding Author: Haya Langerman, Beds \& Herts Postgraduate Medical School, Luton, LU2 8LE, UK, E-mail address: haya.langerman@beds.ac.uk.

Received February 19, 2016

Accepted for publication March 3, 2016 an association between diabetes and the risk of various geriatric conditions (i.e., cognitive impairment, dementia, depression, mobility impairment, disability, and falls) $(5,6)$. They have an increased rate of diabetes-related complications, are much more likely to present with comorbid conditions, and are more susceptiple to the adverse effects of some . glucose-lowering therapies.

Adherence to treatment is a key factor in achieving therapeutic success. Treatment satisfaction is an important determinant of patients overall health-related decisions such as adherence and willingness to continue treatment (7-9). It is defined as the patient's evaluation of the process of taking the medication and the outcomes associated with the medication (10). It is an essential measure of treatment effectiveness as some treatments with proven efficacy in clinical trials are less effective when prescribed in routine clinical practice where there is no intensive follow-up to ensure adherence. However, treatment satisfaction is not an easy item to measure as it depends not only on the clinical outcomes achieved such as symptom resolution, control of the disease progression and prevention, but also on factors such as the route 
Table 1

Study listing

\begin{tabular}{|c|c|c|c|c|c|c|}
\hline Author & Questionnaire & $\begin{array}{l}\text { Number of } \\
\text { items }\end{array}$ & $\begin{array}{l}\text { Europe/US/Ex } \\
\text { US }\end{array}$ & $\begin{array}{l}\text { Type of } \\
\text { publication }\end{array}$ & Funding source & $\begin{array}{l}\text { Cronbach } \\
\text { Alpha }\end{array}$ \\
\hline $\begin{array}{l}\text { Atkinson et al. } \\
\text { (16) }\end{array}$ & $\begin{array}{l}\text { Treatment Satisfaction } \\
\text { Questionnaire for } \\
\text { Medication (TSQM) }\end{array}$ & 14 & USA & Full & Pfizer & 0.87 \\
\hline Ruiz et al. (18) & $\begin{array}{l}\text { Treatment Satisfaction with } \\
\text { Medicines Questionnaire } \\
\text { (SATMED-Q) }\end{array}$ & 17 & Europe & Full & Pfizer & 0.89 \\
\hline Bradley et al. (15) & $\begin{array}{l}\text { Diabetes Treatment } \\
\text { Satisfaction Questionnaire } \\
\text { (DTSQ) }\end{array}$ & 8 & Europe & Full & Not reported & \\
\hline $\begin{array}{l}\text { Anderson et al. } \\
\text { (21) }\end{array}$ & $\begin{array}{l}\text { Diabetes Medication } \\
\text { Satisfaction Tool (DMSAT) }\end{array}$ & 16 & USA & Full & Merck Inc & $0.89-0.95$ \\
\hline Peyrot et al. (19) & $\begin{array}{l}\text { Diabetes Medication System } \\
\text { Rating Questionnaire (DMS- } \\
\text { RQ) }\end{array}$ & 12 & USA & Full & Genentech & 0.82 \\
\hline Donatti et al. (17) & $\begin{array}{l}\text { Satisfaction with Oral } \\
\text { Anti-Diabetic Agent Scale } \\
\text { (SOADAS) }\end{array}$ & 6 & USA & Full & $\begin{array}{l}\text { GlaxoSmith- } \\
\text { Kline }\end{array}$ & 0.86 \\
\hline Ishii \& Oda. (20) & $\begin{array}{l}\text { Oral Hypoglycemic Agent } \\
\text { Questionnaire (OHA-Q) }\end{array}$ & 20 & Japan & Full & Not reported & $0.743-0.902$ \\
\hline
\end{tabular}

and ease of drug administration, and drug tolerability. Overall treatment satisfaction in diabetes consists of the patient's appraisal of three main treatment-related parameters: efficacy, side effects, and treatment burden or inconvenience. However, in older people with diabetes, outcomes such as hospitalisation rates, quality of life, fall rates, instrumental daily living restrictions and admission rates to care homes assume more importance and should also be considered when assessing treatment satisfaction $(11,12)$.

Predictors of treatment satisfaction may differ significantly between patients and it cannot be assumed that generic or disease-specific instruments with evidence of good measurement properties in a younger population will perform as well with an older population. For example, older people with type 2 diabetes are more worried about adverse events, have trouble remembering to take their medication or require assistance from another person in order to take their medication (13). In addition, multiple comorbidities, as is commonly found in older populations, are associated with greater decrements in quality-of-life and well-being (14). Consequently, when assessing treatment satisfaction it is important to use a questionnaire that focuses on areas relevant to the target population. For example, older people with type 2 diabetes are particularly at risk of hypoglycaemia and may be less satisfied with treatments that increase this risk. There are several questionnaires that evaluate treatment satisfaction for people with diabetes: Diabetes Treatment Satisfaction Questionnaire (DTSQ) (15), Treatment Satisfaction Questionnaire for Medication (TSQM) (16), Satisfaction with Oral Anti-Diabetic Agent Scale (SOADAS) (17),
Treatment Satisfaction with Medicines Questionnaire (SATMED-Q) (18), Diabetes Medication System Rating Questionnaire (DMSRQ) (19), and Oral Hypoglycaemic Agent Questionnaire (OHA-Q) (20). Currently, no treatment satisfaction questionnaires have been designed and validated specifically for older people with type 2 diabetes. This review aims to examine the main validated questionnaires in the area of treatment satisfaction in type 2 diabetes and to assess their applicability to older people.

\section{Methods}

ProQuest, PubMed, HeinOnline, ScienceDirect, Academic One File, general OneFile and MEDLINE scientific literature databases were searched from $1 / 1 / 1980$ to $1 / 4 / 2014$ to identify treatment satisfaction questionnaires validated in diabetes for use in patients receiving oral antidiabetes therapies; insulin-specific questionnaires were not included. Search terms for ProQuest and PubMed included 'treatment satisfaction, 'diabetes',' older', 'elderly', 'questionnaires', 'assessment', 'evaluation'. Seven questionnaires were selected based on their validity in patients with diabetes (Table 1). Data extraction was performed to summarise key components of the studies including study design, demographic characteristics including age, choice of domains and items.

\section{Results}

The literature search identified seven questionnaires that had been validated in diabetes. Of these, two 


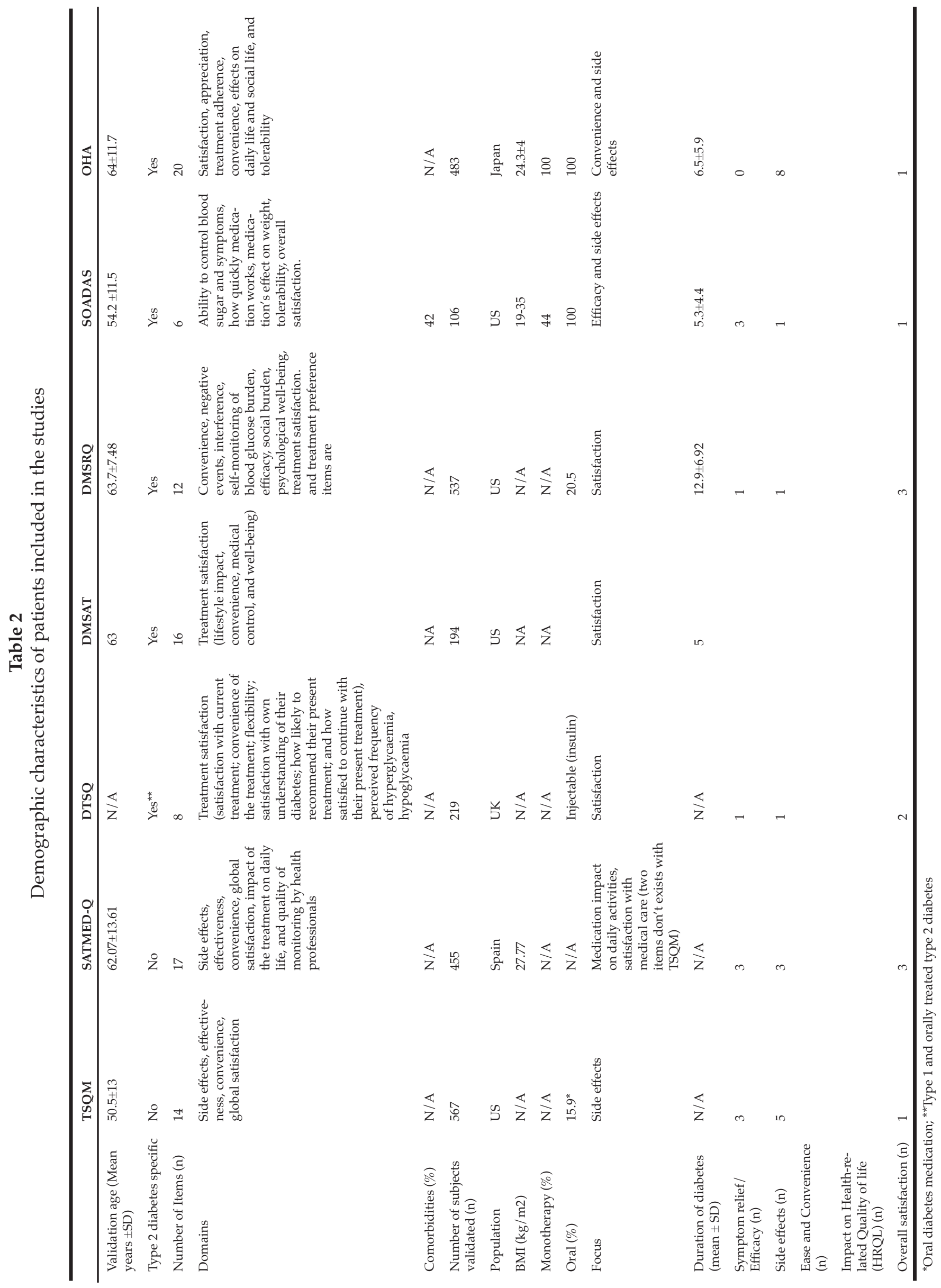


Table 3

Items included in each questionnaire

\begin{tabular}{|c|c|c|c|c|c|c|c|}
\hline & TSQM & SATMED-Q & DTSQ & DMSAT & DMSRQ & SOADAS ${ }^{*}$ & OHA \\
\hline $\begin{array}{l}\text { Satisfaction with current } \\
\text { medication }\end{array}$ & yes & yes & Yes & yes & yes & yes & yes \\
\hline $\begin{array}{l}\text { Comparison of current } \\
\text { medication with previous } \\
\text { medication }\end{array}$ & & & & & yes & & \\
\hline convenience & yes & yes & Yes & yes & yes & & \\
\hline Ease of use & yes & & & yes & yes & & \\
\hline flexibility & yes & & Yes & yes & & & yes \\
\hline Disease knowledge & & yes & Yes & & & & \\
\hline Diabetes complications & & & & & yes & yes & \\
\hline continuity & & yes & yes & & yes & & yes \\
\hline Adherence (forgetting) & & & & & & & yes \\
\hline $\begin{array}{l}\text { Size of tablets, drug } \\
\text { handling }\end{array}$ & & yes & & & yes & & yes \\
\hline $\begin{array}{l}\text { Peer pressure (seen by } \\
\text { others) }\end{array}$ & & & & & yes & & yes \\
\hline Regular meals burden & & & & yes & yes & & yes \\
\hline $\begin{array}{l}\text { Timing of medication } \\
\text { burden }\end{array}$ & yes & yes & & & yes & & yes \\
\hline Dosing frequency & yes & yes & & yes & yes & & yes \\
\hline $\begin{array}{l}\text { Blood glucose monitoring } \\
\text { burden }\end{array}$ & & & & yes & yes & & \\
\hline Onset of action & yes & & & & & yes & \\
\hline General safety & yes & & & & & yes & \\
\hline Hyperglycaemia & & & Yes & & yes & yes & \\
\hline Hypoglycaemia & & & Yes & yes & yes & yes & \\
\hline GI adverse events & & & & & yes & & yes \\
\hline Skin adverse events & & & & & yes & & \\
\hline Weight gain & & & & & yes & yes & yes \\
\hline Appetite & & & & & yes & & yes \\
\hline HbA1c satisfaction & & & & yes & yes & yes & yes \\
\hline $\begin{array}{l}\text { Implication of adverse } \\
\text { events on daily activities, } \\
\text { leisure, physical activity }\end{array}$ & yes & yes & & & yes & & \\
\hline $\begin{array}{l}\text { Friends / family treatment } \\
\text { concerns }\end{array}$ & & & & & yes & & \\
\hline Impact of medicine & yes & yes & & yes & yes & & \\
\hline General efficacy & yes & yes & & yes & & yes & \\
\hline General feel & yes & & & yes & yes & & \\
\hline Advantages & $\begin{array}{l}\text { Measures ease of } \\
\text { use and overall } \\
\text { satisfaction }\end{array}$ & $\begin{array}{l}\text { Explores } 2 \text { extra } \\
\text { dimensions to } \\
\text { TSQM: impact of } \\
\text { treatment on daily } \\
\text { life and quality } \\
\text { of monitoring by } \\
\text { health professio- } \\
\text { nals }\end{array}$ & $\begin{array}{l}\text { Diabetes specific } \\
\text { (type } 1 \text { or type } \\
2 \text { diabetes). Can } \\
\text { measure changes } \\
\text { in satisfaction } \\
\text { with treatment. } \\
\text { Widely used }\end{array}$ & $\begin{array}{l}\text { Diabetes } \\
\text { specific. } \\
\text { Measures } \\
\text { treatment } \\
\text { satisfaction } \\
\text { for all types } \\
\text { of treatment } \\
\text { regimens } \\
\text { from simple } \\
\text { to complex }\end{array}$ & $\begin{array}{l}\text { Very com- } \\
\text { prehensive } \\
\text { question- } \\
\text { naire with } \\
9 \text { subscales. } \\
\text { Diabetes } \\
\text { specific }\end{array}$ & $\begin{array}{l}\text { Specific } \\
\text { for oral } \\
\text { antidiabetes } \\
\text { agents. Vali- } \\
\text { dated in } 20 \\
\text { languages }\end{array}$ & $\begin{array}{l}\text { Specific } \\
\text { for oral } \\
\text { antidia- } \\
\text { betes } \\
\text { agents. }\end{array}$ \\
\hline Disadvantages & Generic & Generic & & & & & \\
\hline
\end{tabular}


were general questionnaires: Treatment Satisfaction Questionnaire for Medication (TSQM) (16) and Treatment Satisfaction with Medicines Questionnaire (SATMED-Q) (18); and five were diabetes-specific: Diabetes Treatment Satisfaction Questionnaire (DTSQ) (15), Diabetes Medication Satisfaction Tool (DMSAT) (21), Diabetes Medication System Rating Questionnaire (DMSRQ) (19), Satisfaction with Oral Anti-Diabetic Agent Scale (SOADAS) (17), and Oral Hypoglycaemic Agent Questionnaire (OHA-Q) (20) (Tables 2 and 3). In addition, the search also identified a quality-of-life questionnaire, the Audit of Diabetes-Dependent Quality of Life (ADDQoL) Senior, which although it looks at quality of life rather than treatment satisfaction is included here as it is the only assessment tool specifically developed for older people with type 2 diabetes (22).

\section{General questionnaires}

\section{Treatment Satisfaction Questionnaire for Medication (TSQM)}

The TSQM is a general tool for assessing patients' satisfaction with medications designed to treat, control, or prevent a wide variety of conditions. It includes 14 items (Table 2) and has been validated across a wide range of diseases, including type 1 diabetes (16). However, unlike the DTSQ, this measure does not include diabetesspecific items and is therefore unlikely to reliably measure treatment satisfaction with oral antihyperglycaemic agents. In the validation study, respondents' age ranged from 18 to 88 years, with a mean of 50.5 (16).

Although it is a general questionnaire, the TSQM has been used in several studies of people treated with oral antidiabetes agents (23-26). These studies showed that the experience of hypoglycaemia was associated with lower global satisfaction. Marrett et al also found significantly lower scores for the side-effects domain in patients reporting hypoglycaemia compared with those who did not $(P \leq 0.001)(23)$. Alvarez-Guisasola et al observed that experience of hypoglycaemia was associated with a negative effect on all domains $(\mathrm{P}<0.001$ for all comparisons) (25). Similar results were found in the Walz et al study, where patients (mean age 69 years) with moderate or worse symptoms of hypoglycaemia indicated several dimensions where they were less satisfied with their antihyperglycaemic medication regimen than patients with no or mild symptoms (26).

\section{Treatment Satisfaction with Medicines Questionnaire (SATMED-Q)}

The SATMED-Q is a multidimensional generic questionnaire that was developed to address some of the limitations of the TSQM questionnaire. It explores the same dimensions as the TSQM and two additional dimensions (impact of the treatment on daily life and quality of monitoring by health professionals). These dimensions have been highlighted by patients as important components of medical care. The questionnaire has been designed for use in patients with any chronic illness and undergoing any type of prolonged pharmacological treatment. The questionnaire has been shown to be a reliable and valid measure of treatment satisfaction in a number of chronic diseases including type 2 diabetes (18), and has been shown to be sensitive to changes in patients' satisfaction with treatment, although this has not been tested in diabetes (27). A search of the literature found no further trials of its use in diabetes.

\section{Diabetes-specific questionnaires}

\section{Diabetes Treatment Satisfaction Questionnaire (DTSQ)}

In its original 'status' format, the DTSQ was designed to prospectively measure satisfaction with diabetes treatment regimens among patients with type 1 or type 2 diabetes. The instrument is comprised of eight items, each rated on a 7-point Likert scale ranging from 0 to 6 (15). The questionnaire has been used in a number of clinical trials evaluating new diabetes treatments. However, the DTSQ measures satisfaction at one point in time, e.g How satisfied are you with your current treatment? The sensitivity to change of the DTSQ is therefore limited, and ceiling effects are often seen, where maximum or closeto-maximum scores at baseline provide little opportunity for registering improvement in satisfaction with the treatment or strategy being assessed. A 'change' format of the DTSQ was designed to overcome the ceiling effects of the 'status' version and to measure change in satisfaction (28). This instrument contains the same eight items as the DTSQ-status version, but asks patients to consider their satisfaction with their current treatment compared with their previous treatment. When used together in a clinical trial setting, the status version, used at baseline, permits assessment of absolute levels of satisfaction, while the change version measures relative change, reflecting increased or decreased satisfaction or no change in satisfaction.

Using the DTSQ status version, Biderman et al found that lower treatment satisfaction was related to difficulties in adherence to taking medications (7). The mean age in this study was 67 years. They also found that insulintreated patients were least satisfied with treatment. This was also the case in the Petterson et al study, which specifically examined treatment satisfaction in older people ( $\geq 60$ years) with diabetes (mean age 71 years) (29). Aside from the obvious fact that injecting insulin is less comfortable than taking a pill, this outcome may also reflect patients' perceptions that insulin treatment means that their health status has deteriorated. Another possible explanation is that people with type 2 diabetes who 
need insulin, have longer disease duration, with more complications. Diabetes complications were also found to be associated with low satisfaction. Furthermore, less satisfaction was associated with having any complication at all, and there was a constant decline in treatment satisfaction with increased number of complications. In contrast to another study, which showed better treatment satisfaction in older patients than younger patients (30), neither the Biderman nor Petterson et al studies found an association between age and treatment satisfaction $(7,29)$.

Some studies have reported that treatment satisfaction decreases with higher HbA1c levels $(30,31)$. However, as only a minority of patients may be aware of the term 'HbA1c,' this could be a possible reason for the lack of correlation between $\mathrm{HbA} 1 \mathrm{c}$ levels and treatment satisfaction. In the Biderman and Petterson et al studies, there was no correlation between $\mathrm{HbA} 1 \mathrm{c}$ and satisfaction, but lower satisfaction was found at $\mathrm{HbA} 1 \mathrm{c}>7 \%(\mathrm{mmol} / \mathrm{L})$ $(7,29)$.

\section{Diabetes Medication Satisfaction Tool (DMSAT)}

The 16-item DMSAT tool measures satisfaction with the patient's diabetes medication regimens (Table 2) (21). Responses are summed and converted to a score from 0 to 100 for each subscale and overall, with higher scores representing more satisfaction.

The scale has been used to measure treatment satisfaction in a UK survey of patients with type 2 diabetes designed to evaluate associations between hypoglycaemic events and patient-reported outcomes (32). Medication satisfaction was lower among those who experienced $\geq 1$ hypoglycaemic event in the 4 weeks prior to the survey $(\mathrm{P}<0.0001)$. People in old age were not recruited, the mean age of participants in the survey was $58.8 \pm 10.9$ years.

\section{Diabetes Medication System Rating Questionnaire (DMSRQ)}

The DMSRQ was developed to assess satisfaction with any diabetes medication, oral or injectable, used to control blood glucose (19). The DMSRQ contains nine scales, scored on a 0-to-100 scale (a higher score indicates greater levels of the construct measured) (Table 2). It is also available in a short form (33). In the validation study patients were aged 40-64 years (19). In contrast to the DTSQ, DMSRQ can distinguish between certain components of the diabetes treatment such as medication, diet, exercise and glucose monitoring. Other than the validation studies a search of the literature found no further trials of its use in diabetes.

\section{Satisfaction with Oral Anti-Diabetic Agent Scale (SOADAS)}

SOADAS was the first questionnaire to evaluate people with type 2 diabetes on oral anti-diabetes agents (17). SOADAS has cross-cultural face validity having been translated and validated in 20 languages to ensure that new language versions are sensitive to cultural expressions. Unlike the DTSQ, which was developed based on insulin-treated patients, the six-item SOADAS scale includes items on side effects as well as medication effects on body weight, which may be critical in differentiating treatment satisfaction among patients on different oral anti-diabetes agents (Table 2 ). The findings from the evaluation study indicate that SOADAS is a valid and reliable measure of patient satisfaction with oral antidiabetes medications, but a limitation of the SOADAS questionnaire is that validation was only carried out on a sample of US patients, with a BMI between 19 and 35. In addition, the questionnaire does not evaluate the impact on daily life, and side effects other than weight gain are reduced to one item (tolerability). A search of the literature did not find any studies that have used SOADAS.

\section{Oral Hypoglycaemic Agent Questionnaire (OHA-Q)}

The OHA-Q was developed by Japanese researchers because of a lack of current tools to clarify differences among the oral agents for type 2 diabetes (20). For example, the SOADAS questionnaire oversimplified tolerability aspects as well as lacking evaluation of the impact on daily life. The 20-item OHA-Q provides information useful for the selection of oral agents and unlike SOADAS is also available in Japanese. Subjects in the validation study had type 2 diabetes and had been treated with a single oral antidiabetes agent for the past 1 month or longer. They had to be a least 20 years old, but there was no upper age cut-off.

\section{The Audit of Diabetes-Dependent Quality of Life (ADDQoL)}

ADDQoL is a diabetes-specific measure that assesses the impact of diabetes on 18 life domains such as "working life," "family life," "freedom to eat as I wish," and "self-confidence" and has proven to be sensitive to changes in treatment $(22,34)$. Individuals with diabetes complications reported a significantly greater negative impact of diabetes on QoL than those without complications $(\mathrm{P}<0.001)$. It is of interest to note that the overall impact of diabetes on QoL in the validation study population was profoundly negative, but accompanying DTSQ findings showed a relatively high satisfaction with treatment. Thus, if treatment satisfaction had 
been used as an indicator of QoL in this study (22), the negative impact of diabetes on QoL would not have been acknowledged, and the high levels of treatment satisfaction may have been misinterpreted to suggest that patients had good QoL. Use of ADDQoL with people with type 1 or type 2 diabetes has shown, on average, a negative impact of diabetes on all domains (22).

In general, these findings indicate that ADDQoL is sensitive to the effects of diabetes (including both its treatment and complications) that cannot be captured by the measurement of treatment satisfaction alone. ADDQoL identifies more negative psychological outcomes than diabetes-specific treatment satisfaction scales such as the DTSQ, and thus it is likely to be even more sensitive to improvements following change to a new treatment that protects aspects of life that are important for QoL. In particular, the DIABQoL+ study has shown that restrictions on dietary freedom have a major negative impact on QoL, suggesting that treatments that increase dietary freedom without loss of metabolic control will improve QoL for many patients (35).

\section{ADDQoL Senior}

Quality-of-life questionnaires differ from treatment satisfaction questionnaires and ADDQoL Senior is only mentioned here because it is the only assessment tool that has been specifically developed for assessing quality of life in older people with type 2 diabetes, particularly carehome residents (36). In the validation, 'independence' was the aspect of life reported to be most important for quality of life and had the most negative weighted impact score, followed by 'freedom to eat as I wish'. Thus, further research is required to examine the relationship between 'independence' and drug administration related aspects that are likely to be affected by reduced independence and therefore to reduce the level of satisfaction. ADDQoL Senior is being validated in the ongoing MID-Frail study in frail and pre-frail subjects aged $\geq 70$ years with type 2 diabetes (37).

\section{Discussion}

A review of the literature reveals that a number of treatment satisfaction measures are available, but few have been validated in type 2 diabetes and none appears suited to capturing the satisfaction of older adults with type 2 diabetes. Only SOADAS and OHA-Q are specific to oral antidiabetes therapies. TSQM, and SATMED-Q are general questionnaires designed to assess satisfaction with medication in chronic conditions, and are not specific to type 2 diabetes. Mean age slightly differs between the questionnaires, whilst the patient population in OHA-Q is older compared with the other questionnaires.

The main focus in OHA-Q and TSQM is safety-related items such as adverse events and their implication on physical and mental activities. OHA-Q lists eight different items referring to adverse events such as hypoglycaemia, weight gain and gastrointestinal symptoms. OHA-Q was tested among patients on monotherapy only and therefore may enable comparisons between the different classes of oral therapies to be made. While the mean age in the OHA-Q validation was slightly higher compared with the other questionnaires, none of the questionnaires has been validated in patients $>70$ years. The choice of items is extremely important especially as there are specific items that are more relevant to older people such as drug administration related aspects as well as adverse events. Both OHA-Q and SOADAS looked at satisfaction with current therapy, weight gain related items and efficacy of the drug. As opposed to SOADAS, OHA-Q includes more items related to safety of the therapy while SOADAS focuses heavily on efficacy-related items. Older people with type 2 diabetes are in many cases frail and suffer from comorbidities. It is therefore important to provide a balance between efficacy- and safety-related items.

Due to the prolonged and progressive nature of chronic diseases such as diabetes, poor adherence can adversely affect the long-term effectiveness of a drug. An assessment of a patient's treatment satisfaction is therefore useful to help identify those at risk of poor adherence, and enable physicians to target their interventions toward the aspects responsible for this. An important barrier to effective diabetes self-management is hypoglycaemia associated with diabetes medication (38). A number of studies have shown that hypoglycaemia is significantly associated with poorer health-related quality of life and patient outcomes, achievement of treatment goals, and healthcare utilization $(25,32$, 39-41). Older people with diabetes are at greater risk for hypoglycaemia; normal aging may contribute to failure in counter regulatory responses (neurohumoral responses, subject awareness) to hypoglycaemia (42), symptoms may be mistaken for other conditions associated more commonly with advanced aged, and several treatments, including the sulphonylureas, other insulin secretagogues, and insulin, may either contribute to or directly cause it (43). In a population-based, retrospective, 4-year cohort study in 19,932 patients, frail older individuals ( $>80$ years) using multiple medications and frequently hospitalised were at greater risk for hypoglycaemia (risk ratio $=1.8 ; 95 \% \mathrm{CI}, 1.4-2.3 ; \mathrm{P}=0.05$ ) than healthier individuals of the same age (44).

In addition to providing useful insight into the patient's perspective on their current treatment, treatment satisfaction is a valuable endpoint for clinical studies of treatments for chronic conditions where treatment compliance and adherence are considered issues (45). Thus, when new treatments have comparable efficacy, treatment satisfaction can be used to examine whether drug differences other than clinical efficacy have an impact on outcomes that may be important to patients. However, direct comparisons of satisfaction scores between studies are problematic due to the diversity of 
assessment instruments used. There is also currently no evidence of reliability or validity of existing instruments in older individuals with type 2 diabetes.

To date, treatment satisfaction has been used in only a limited way to support EMEA drug approvals, which may be due in part to a limited number of appropriate treatment satisfaction measures. Given the high proportion of older individuals with type 2 diabetes (6, $46)$, there is an urgent need for treatment satisfaction questionnaires to be developed and validated in older populations with type 2 diabetes so that clinical trials can use these measures to differentiate between alternative treatments.

\section{Conclusion}

Although older people with type 2 diabetes are an important and growing group, no validated treatment satisfaction measure is available to assess satisfaction with oral antidiabetes medication in this population. Future research should focus on developing new measures or adapting existing measures and validating them in a range of older populations with type 2 diabetes to inform treatment decisions on optimal therapy. In addition to medication effectiveness, side effects, and convenience of use, such a questionnaire should include an extended range of concerns, such as dosing schedules, time spent managing diabetes, and integrating medication regimens into ones lifestyle or routine, which may become important as the treatment regimen grows in complexity. Concerns related to older people in particular should also be included such as functional autonomy, independence, fall rates, hospitalization rates, and admission rates to care home. Of the currently available questionnaires, OHA-Q and SOADAS appear best suited to assessing treatment satisfaction in older people with type 2 diabetes, although adjustments may be required to ease reading and completion of the questionnaire.

Conflict of interest: The authors declare no conflict of interest. H. Langerman is an employee of Merck Sharp and Dohme, UK. The authors were supported by a medical writer who was funded by Merck Sharp and Dohme. The authors had complete editorial control over the manuscript, which represents the views of the authors.

\section{References}

1. Department of Health. National Service Framework for Older People. March 2001. Available from: https:/ / www.gov.uk/government/uploads/system/ uploads / attachment_data / file/198033 / National_Service_Framework_for_ Older_People.pdf. Last accessed March 2015.

2. International Diabetes Federation [webpage on the Internet] IDF Diabetes Atlas. 6th ed. Brussels, Belgium: International Diabetes Federation 2013. [Accessed January 1, 2014]. Available from:http://www.idf.org/ diabetesatlas.

3. Fagot-Campagna A, Bourdel-Marchasson I, Simon D. Burden of diabetes in an aging population: prevalence, incidence, mortality, characteristics and quality of care. Diabetes Metab 2005;31:5S35-5S52.

4. Sinclair A, Morley JE, Rodriguez-Mañas L, Paolisso G, Bayer T, Zeyfang A, et al. Diabetes mellitus in older people: position statement on behalf of the International Association of Gerontology and Geriatrics (IAGG), the European Diabetes Working Party for Older People (EDWPOP), and the International Task Force of Experts in Diabetes. J Am Med Dir Assoc 2012;13:497-502.
5. Lu FP, Lin KP, Kuo HK. Diabetes and the risk of multi-system aging phenotypes: a systematic review and meta-analysis. PLoS One 2009;4:e4144.

6. Sinclair A, Dunning T, Rodriguez-Mañas L. Diabetes in older people: new insights and emaining challenges. Lancet Diabetes Endocrinol 2015;3:275-85.

7. Biderman A, Noff E, Harris SB, Friedman N, Levy A. Treatment satisfaction of diabetic patients: what are the contributing factors? Fam Pract 2009;26:102 8 .

8. Barbosa CD, Balp MM, Kulich K, Germain N, Rofail D. A literature review to explore the link between treatment satisfaction and adherence, compliance, and persistence. Patient Prefer Adherence 2012;6:39-48.

9. Pollack MF, Purayidathil FW, Bolge SC, Williams SA. Patient-reported tolerability issues with oral antidiabetic agents: Associations with adherence treatment satisfaction and health-related quality of life. Diabetes Res Clin Pract 2010;87:204-10.

10. Weaver M, Patrick DL, Markson LE, Martin D, Frederic I, Berger M. Issues in the measurement of satisfaction with treatment. Am J Manag Care 1997;3:579-94.

11. Bourdel-Marchasson I, Sinclair A. Elderly patients with type 2 diabetes mellitus-the need for high-quality, inpatient diabetes care. Hosp Pract (1995) 2013;41:51-6.

12. Bourdel-Marchasson I, Druet C, Helmer C, Eschwege E, Lecomte P, Le-Goff M, Sinclair AJ, Fagot-Campagna A. Correlates of health-related quality of life in French people with type 2 diabetes. Diabetes Res Clin Pract 2013;101:22635 .

13. Brown SE, Meltzer D, Chin MH, Huang ES. Perceptions of quality-of-life effects of treatments for diabetes mellitus in vulnerable and nonvulnerable older patients. J Am Geriatr Soc 2008;56:1183-90.

14. Wikman A, Wardle J, Steptoe A. Quality of life and affective well-being in middle-aged and older people with chronic medical illnesses: a crosssectional population based study. PLoS One 2011;6:e18952.

15. Bradley C. Diabetes treatment satisfaction questionnaire. In: Bradly C (ed.). Handbook of Psychology and Diabetes: A Guide to Psychological Measurement in Diabetes Research and Practice. Chur, Switzerland: Harwood Academic Publisher, 1994:111-32.

16. Atkinson MJ, Sinha A, Hass SL, Colman SS, Kumar RN, Brod M, et al. Validation of a general measure of treatment satisfaction, the Treatment Satisfaction Questionnaire for Medication (TSQM), using a national panel study of chronic disease. Health Qual Life Outcomes 2004;2:12.

17. Donatti C, Wild D, Horblyuk R, Beusterien KB, Anderson RT, Arondekar B, et al. Psychometric evaluation of the Satisfaction with Oral Anti-Diabetic Agent Scale (SOADAS). Diabetes Res Clin Pract 2008;80:108-13.

18. Ruiz MA, Pardo A, Rejas J, Soto J, Villasante F, Aranguren JL. Development and Validation of the "Treatment Satisfaction with Medicines Questionnaire" (SATMED-Q). Value Health 2008;913-26.

19. Peyrot M, Harshaw Q, Shillington AC, Xu Y, Rubin RR. Care delivery validation of a tool to assess medication treatment satisfaction in patients with type 2 diabetes: the Diabetes Medication System Rating Questionnaire (DMSRQ). Diabet Med 2012;29:1060-6.

20. Ishii H, Oda E. Reproducibility and validity of a satisfaction questionnaire on hypoglycemic agents: the Oral Hypoglycemic Agent Questionnaire (OHA-Q). Diabetol Int 2012;3:152-63.

21. Anderson RT, Girman CJ, Pawaskar MD, Camacho FT, Calles J, Kelly WS, DeMuro C, Balkrishnan R. Diabetes Medication Satisfaction Tool: a focus on treatment regimens. Diabetes Care 2009, 32:51-3.

22. Bradley C, Todd C, Gorton T, Symonds E, Martin A, Plowright R. The development of an individualized questionnaire measure of perceived impact of diabetes on quality of life: the ADDQoL. Qual Life Res 1999;8:79-91.

23. Marrett E, Stargardt T, Mavros P, Alexander CM. Patient reported outcomes in a survey of patients treated with oral antihyperglycaemic medications: associations with hypoglycaemia and weight gain. Diabetes Obes Metab 2009;11:1138-44.

24. Stargardt T, Gonder-Frederick L, Krobot KJ, Alexander CM. Fear of hypoglycaemia: defining a minimum clinically important difference in patients with type 2 diabetes. Health Qual Life Outcomes 2009;7:91.

25. Alvarez Guisasola F, Tofé Povedano S, Krishnarajah G, Lyu R, Mavros P, Yin D. Hypoglycaemic symptoms, treatment satisfaction, adherence and their associations with glycaemic goal in patients with type 2 diabetes mellitus: Findings from the Real-Life Effectiveness and Care Patterns of Diabetes Management (RECAP-DM) Study. Diabetes Obes Metab 2008;10(Suppl 1):2532.

26. Walz L, Pettersson B, Rosenqvist U, Deleskog A, Journath G, Wändell P. Impact of symptomatic hypoglycemia on medication adherence, patient satisfaction with treatment, and glycemic control in patients with type 2 diabetes. Patient Prefer Adherence 2014;8:593-601.

27. Rejas J, Ruiz M, Pardo A, Soto J. Detecting changes in patient treatment satisfaction with medicines: the SATMED-Q. Value Health 2013;16:88-96.

28. Bradley C. Diabetes treatment satisfaction questionnaire. Change version for use alongside status version provides appropriate solution where ceiling effects occur. Diabetes Care 1999:22:530-2.

29. Petterson T, Pauline L, Hollis S, Young B, Newton P, Dornan T. Well-being and treatment satisfaction in older people with diabetes. Diabetes Care 1998;31:930-5. 
30. Ken W, Koopmanshap MA, Stolk RP, Rutten GEM, Wolffenbuttel BHR, Niessen LW. Health-related quality of life and treatment satisfaction in Dutch patients with type 2 diabetes. Diabetes Care 2002;25:458-63.

31. Bradley C, Lewis KS. Measures of psychological well-being and treatment satisfaction developed from the responses of people with tablet-treated diabetes. Diabet Med 1990;7:445-51.

32. Mitchell BD, Vietri J, Zagar A, Curtis B, Reaney M. Hypoglycaemic events in patients with type 2 diabetes in the United Kingdom: associations with patient-reported outcomes and self-reported HbA1c. BMC Endocr Disord 2013;13:59.

33. Peyrot M, Xu Y, Rubin RR. Development and validation of the Diabetes Medication System Rating Questionnaire-Short Form. Diabet Med 2014;31:1237-44.

34. Speight J, Bradley C. The ADKnowl: identifying knowledge deficits in diabetes care. Diabet Med 2001;18:626-33.

35. Bradley C, Speight J. Patient perceptions of diabetes and diabetes therapy: assessing quality of life. Diabetes Metab Res Rev 2002;18(Suppl 3):S64-9.

36. Speight J, Sinclair AJ, Browne JL, Woodcock A, Bradley C. Assessing the impact of diabetes on the quality of life of older adults living in a care home: validation of the ADDQoL Senior. Diabet Med 2013;30:74-80.

37. Rodríguez-Mañas L, Bayer AJ, Kelly M, Zeyfang A, Izquierdo M, Laosa O, et al; ${ }^{*}$ on behalf of the MID-Frail Consortium. An evaluation of the effectiveness of a multi-modal intervention in frail and pre-frail older people with type 2 diabetes - the MID-Frail study: study protocol for a randomised controlled trial. Trials 2014;15:34.

38. Seaquist ER, Anderson J, Childs B, Cryer P, Dagogo-Jack S, Fish L, et al Hypoglycemia and diabetes: a report of a workgroup of the American Diabetes Association and The Endocrine Society. Diabetes Care 2013;36:138495.
39. Williams SA, Shi L, Brenneman SK, Johnson JC, Wegner JC, Fonseca V. The burden of hypoglycemia on healthcare utilization, costs, and quality of life among type 2 diabetes mellitus patients. J Diabetes Complications 2012;26:399-406.

40. Marrett E, Radican L, Davies MJ, Zhang Q. Assessment of severity and frequency of self-reported hypoglycemia on quality of life in patients with type 2 diabetes treated with oral antihyperglycemic agents: a survey study. BMC Res Notes 2011;4:251.

41. Shi L, Shao H, Zhao Y, Thomas NA. Is hypoglycemia fear independently associated with health-related quality of life? Health Qual Life Outcomes 2014;12:167.

42. Matyka K, Evans M, Lomas J, Cranston I, Macdonald I, Amiel SA. Altered hierarchy of protective responses against severe hypoglycemia in normal aging in healthy men. Diabetes Care 1997;20:135-41.

43. American Diabetes Association. Standards of medical care in diabetes-2011. Diabetes Care 2011;34(Suppl 1):S11-S61.

44. Shorr RI, Ray WA, Daugherty JR, Griffin MR. Incidence and risk factors for serious hypoglycemia in older persons using insulin or sulfonylureas. Arch Intern Med 1997;157:1681-6.

45. Roborel de Climens A, Tunceli K, Arnould B, Germain N, Iglay K, Norquist $\mathrm{J}$, et al. Review of patient-reported outcome instruments measuring healthrelated quality of life and satisfaction in patients with type 2 diabetes treated with oral therapy. Curr Med Res Opin 2015;31:643-65.

46. Centers for Disease Control and Prevention. National Diabetes Fact Sheet: National Estimates and General Information on Diabetes and Prediabetes in the United States. Atlanta, GA: US Department of Health and Human Services, Centers for Disease Control and Prevention, 2011. 